\title{
Sequence selective naked-eye detection of DNA harnessing extension of oligonucleotide-modified nucleotides
}

\author{
Daniela Verga, Moritz Welter, Andreas Marx* \\ Department of Chemistry and Konstanz Research School Chemical Biology University of Konstanz, Universitätsstrasse 10, 78457 Konstanz, Germany
}

\section{A R T I C L E I N F O}

Keywords:

DNA polymerase

Oligonucleotide-modified nucleotide

Rolling circle amplification

Single-base resolution

Naked-eye detection

\begin{abstract}
A B S T R A C T
DNA polymerases can efficiently and sequence selectively incorporate oligonucleotide (ODN) modified nucleotides and the incorporated oligonucleotide strand can be employed as primer in rolling circle amplification (RCA). The effective amplification of the DNA primer by $\Phi 29$ DNA polymerase allows the sequence selective hybridisation of the amplified strand with a G quadruplex DNA sequence that has horse radish peroxidase like activity. Based on these findings we develop a system that allows DNA detection with single base resolution by naked eye.
\end{abstract}

The intrinsic importance of nucleic acids as biological targets, due to their connection to gene mutation and expression, protein synthesis, heredity, and pathogens, prompted the development of signal amplification strategies to manufacture highly sensitive DNA biosensors for sequence specific DNA detection. ${ }^{1}$ The detec tion of low abundant target DNA plays essential roles in early stage clinical diagnosis and medical treatments for some major diseases like cancer, ${ }^{2}$ environmental monitoring ${ }^{3}$ as well as forensic analy sis. ${ }^{4}$ Particularly, point of care testing (POCT) for nucleic acid detection is highly demanded where suitable facilities are not available and rapid answers are required. ${ }^{5}$ During the past years, PCR based technologies have been vastly exploited for this pur pose. ${ }^{6}$ However, they lack the essential features for device portabil ity due to their need of rigid control of temperature cycling using advanced and expensive instrumentation and their request of highly trained analyst. ${ }^{6 a, 7}$ In order to replace the laborious thermal cycling protocol, isothermal amplification methods have been developed. These methods include loop mediated isothermal amplification (LAMP), ${ }^{8}$ strand displacement amplifica tion (SDA), ${ }^{9}$ rolling circle amplification (RCA), ${ }^{10}$ and helicase dependent amplification (HDA). ${ }^{11}$

So far, several naked eye detection systems have been exploited for nucleic acids and pathogen identification, such as loop medi ated isothermal amplification devices, ${ }^{12}$ solid phase PCR micro plate chip assay, ${ }^{13}$ urease/DNAzyme coupled system, ${ }^{14}$ rolling

\footnotetext{
* Corresponding author.

E-mail address: andreas.marx@uni-konstanz.de (A. Marx).
}

circle amplification coupled to a DNAzyme, ${ }^{15}$ and DNA probe mod ified gold nanoparticles. ${ }^{16}$

Here, we describe a detection system that connects the sequence selective incorporation of an oligonucleotide (ODN) modified nucleotide to a colour generation that can be detected by the naked eye. This approach takes advantage from our previous findings that demonstrate the ability of DNA polymerases to incor porate triphosphates that are modified with bulky structured ${ }^{17}$ and unstructured $^{18}$ single stranded oligonucleotides, and to use those ODN modified nucleotides as primers for rolling circle amplifica tion. ${ }^{18}$ In here, the elongated DNA strand is captured with a com plementary DNA strand that harbours a DNAzyme able to generate a colour signal. Thereby the sequence selective incorpo ration of an ODN modified nucleotide is linked to a signal that is detectable by the naked eye.

The conceptual framework of our approach is depicted in Fig ure 1. The approach is based on performing a primer extension reaction using an immobilized primer. Hybridization of the primer to a complementary DNA template induces the sequence selective incorporation of the ODN modified nucleotide. After washing, the immobilized ODN serves as a primer in rolling circle amplification using a complementary circular template resulting in an extended DNA single strand of repeated sequences. The extended single strand product captures the complimentary $3^{\prime}$ flanking region of a $G$ quadruplex containing DNA. The G quadruplex containing DNA has horse radish peroxidase like activity and thus catalyses the hemin mediated oxidation of $\mathrm{ABTS}^{2}$ by $\mathrm{H}_{2} \mathrm{O}_{2}$ to the corre sponding radical ABTS which results in a green colour. ${ }^{19}$ 


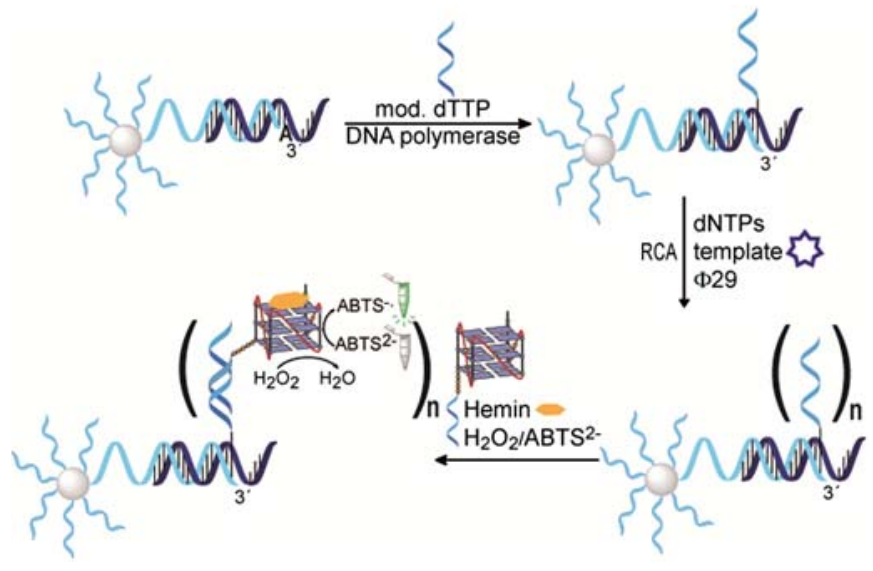

Figure 1. Schematic concept of the assay: Primers are immobilized on beads. The hybridisation of the primer to the target DNA template allows the sequence selective incorporation of the ODN-modified nucleotide (dT*TP). After washing steps, the isothermal amplification is performed in the presence of a circular template that binds to its complementary ODN strand and enables the extension of the complementary primer by multiple copies. For signal generation, the beads are incubated with the G-quadruplex DNAzyme sequence, and after washing steps the addition of hemin, $\mathrm{ABTS}^{2}$, and $\mathrm{H}_{2} \mathrm{O}_{2}$ will induce the signal generation only in cases where the ODN-modified nucleotide was incorporated.

The proficiency of DNA polymerases to process $\mathbf{d T}$ T:TP in primer extension experiments were carried out as previously reported. ${ }^{18}$ We evaluated the acceptance of $\mathbf{d T}^{*} \mathbf{T P}$ in DNA polymerase pro moted primer extension reactions catalysed by the Klenow Frag ment of Escherichia coli DNA polymerase I (KF exo ) (Fig. S2) and by KlenTaq DNA polymerase (Fig. S3). In accordance with previous results, both enzymes process the modified $\mathbf{d T}^{*} \mathbf{T P}$ and incorporate the modified nucleotide in the nascent DNA strand. These results prompted us to explore this system for DNA detection at single base resolution and facilitating naked eye detection following the strategy of Figure 1. We chose to conduct experiments on the sequence context of the $\mathrm{B}$ type Raf kinase (BRAF) gene ${ }^{20}$ to be able to compare the results with those previously obtained by incorpo ration of a nucleotide modified with a G quadruplex derived DNAzyme. $^{17}$

For the development of a DNA detection system, a biotinylated primer probe $(\mathbf{P})$ was immobilized on streptavidin coated beads. Next, single incorporation of an ODN modified nucleotide was per formed by usage of $\mathbf{d T}^{*} \mathbf{T P}$ and a template coding for the insertion of a thymidine (Fig. 2A). Therefore, the beads bearing the immobi lized primer were incubated at $37^{\circ} \mathrm{C}$ for $30 \mathrm{~min}$ in the presence of $K F$ exo , template $\mathbf{T}_{\mathbf{A}}$ and $\mathbf{d T}{ }^{*} \mathbf{T P}$ (for details see Supporting infor mation). After incubation, the beads were washed and subse quently incubated with a G quadruplex DNA strand (G4), harbouring a $3^{\prime}$ flanking sequence that binds to the ODN function alized nucleotide. The beads were washed and subsequently hemin, $\mathrm{ABTS}^{2}$, and $\mathrm{H}_{2} \mathrm{O}_{2}$ were added to the reaction mixture. The results are depicted in Figure 2B. The chromogenic reaction proceeds over time and stationary read out was observed after $1 \mathrm{~h}$ as it has been confirmed by UV measurements of ABTSabsorption at $420 \mathrm{~nm}$ in function of the time (Fig. 2C). As control a reaction in the absence of $\mathbf{d T}^{*} \mathbf{T P}$ was performed, and no signifi cant colour change was detected. We observed a detection limit at $50 \mathrm{nM}$ (Fig. 2B) that is comparable to the value obtained with the previous developed assay that comprise the direct incorpora tion of a $G$ quadruplex modified nucleotide. ${ }^{17}$

Next, we evaluated the ability of the system to discriminate between the presence of two DNA strands differing only at one nucleotide that is localised at the incorporation site. These experi ments were conducted as described before either in the presence of
(A)

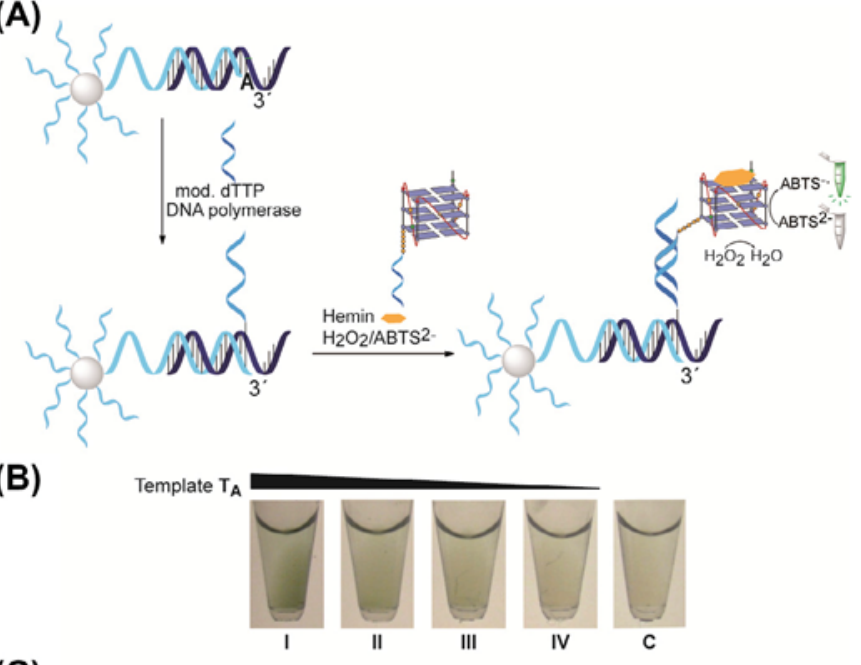

(C)

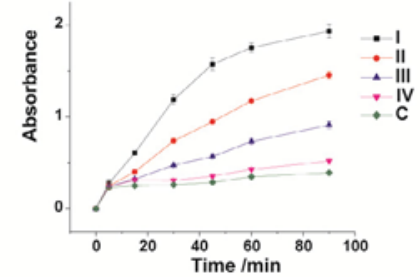

(D)

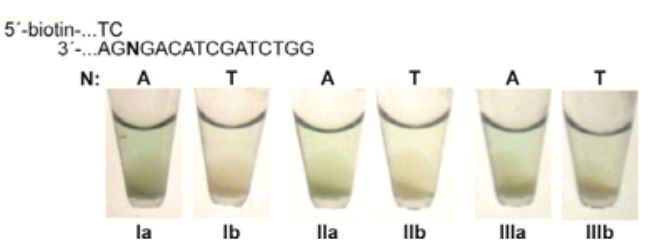

Figure 2. (A) Same as Figure 1 without RCA. (B) Detection limit identification by processing of $\mathbf{d T}^{*} \mathbf{T P}$ with $K F$ exo DNA polymerase at $37^{\circ} \mathrm{C}$ in the presence of different concentrations of template $\left(\mathbf{T}_{\mathbf{A}}\right)$. Signal identification via peroxidase-like activity of the complex hemin/hybridised G-quadruplex DNA strand. Concentration template $\mathbf{T}_{\mathbf{A}}$ : test tube I: $400 \mathrm{nM}$; test tube II: $100 \mathrm{nM}$; test tube III: $50 \mathrm{nM}$; test tube IV: $10 \mathrm{nM}$. Control experiment: test tube C: $400 \mathrm{nM}$ template $\mathbf{T}_{\mathrm{A}}$, experiment performed without $\mathbf{d T}^{*} \mathbf{T P}$. The pictures were taken after $1 \mathrm{~h}$. (C) ABTS absorption at $420 \mathrm{~nm}$ recorded in function of the time after addition of hemin, ABTS $^{2}$, and $\mathrm{H}_{2} \mathrm{O}_{2}$ in caco. KTD buffer $10 \mathrm{mM}$ to the beads. The time points were taken after: 5 , $15,30,45,60$, and $90 \mathrm{~min}$. Concentration canonical template $\left(\mathbf{T}_{\mathbf{A}}\right): 400 \mathrm{nM}$ (I, 12 pmol, black line), $100 \mathrm{nM}$ (II, 3 pmol, red line), $50 \mathrm{nM}$ (III, $1.5 \mathrm{pmol}$, blue line), $10 \mathrm{nM}$ (IV, 0.3 pmol, magenta line), and control (C, green line). (D) Partial DNA sequence of primer and template. Discrimination experiments: template $\mathbf{T}_{\mathrm{A}}$ template $\mathbf{T}_{\mathbf{T}}$ (sequences details see Supporting information). Template $\mathbf{T}_{\mathbf{A}}$ concentrations: test tubes Ia $(400 \mathrm{nM})$, IIa $(100 \mathrm{nM})$, and IIIa $(50 \mathrm{nM})$; template $\mathbf{T}_{\mathbf{T}}$ : test tubes Ib (400 nM), IIb (100 nM), and IIIb (50 nM). The pictures were taken after $1 \mathrm{~h}$.

template $\mathbf{T}_{\mathbf{A}}$, calling for the insertion of a thymidine analogue, or template $\mathbf{T}_{\mathbf{T}}$, calling for the incorporation of an adenosine analogue (Fig. 2D). As expected, little colour change was detected in the presence of template $\mathbf{T}_{\mathbf{T}}$ while in the presence of the canonical tem plate $\mathbf{T}_{\mathbf{A}}$ a significant colour change was observed.

Next, we exploited the ability of DNA polymerases to utilise the incorporated ODN modified nucleotide as a primer in RCA. Thereby the primer should be extended by multiple repeats of a sequence that binds to the G quadruplex DNA strand (G4) that has DNAzyme activity, via its $3^{\prime}$ flanking sequence. This should in turn result in signal amplification. For this purpose, we performed primer exten sion reactions with natural dNTPs in the presence of DNA poly merase and a circular template (cT, see Supplementary information) that is complementary to the ODN of the ODN modified nucleotide. The optimal settings for these experiments that include RCA were obtained by optimising the conditions of the single nucleotide incorporation reaction and by exploring 
conditions that reduce the background. The primer extension was optimised by changing DNA polymerase from KF exo to KlenTaq DNA polymerase. The latter reduces misincorporation that can lead to high background in the control experiments (compare single incorporation experiments of $K F$ exo (line 1, Fig. S2) with the one of KlenTaq DNA polymerase (line 1, Fig. S3). Primer extension reactions were performed at lower temperature than the optimal temperature required for KlenTaq DNA polymerase (see Fig. S4) due to unspecific reactions occurring on the beads by heating for longer times resulting in high background. In addition, to further reduce the background the beads were treated with biotin to block free biotin binding sites on streptavidin. Afterwards, the immobi lized primers were hybridised with template $\mathbf{T}_{\mathbf{A}}$ and submitted to single nucleotide incorporation experiments in the presence of dT*TP. The beads were first incubated at $37^{\circ} \mathrm{C}$ for $90 \mathrm{~min}$ with KlenTaq DNA polymerase, $\mathbf{d T} \mathbf{T}^{*} \mathbf{T P}$ and template $\mathbf{T}_{\mathbf{A}}$. Next, to induce signal amplification, RCA by $\Phi 29$ DNA polymerase was performed. The choice of this DNA polymerase was driven by its ability to incorporate $>70,000 \mathrm{nt}$ per binding event. ${ }^{21}$ Moreover, it has excel lent strand displacement activity and is very stable, which allows efficient DNA synthesis by RCA to continue for hours. ${ }^{21}$ Thus, after washing, we subsequently incubated the beads with $\Phi 29$ DNA polymerase in the presence of circular template cT that binds to its complementary oligonucleotide now tethered to the beads

(A)

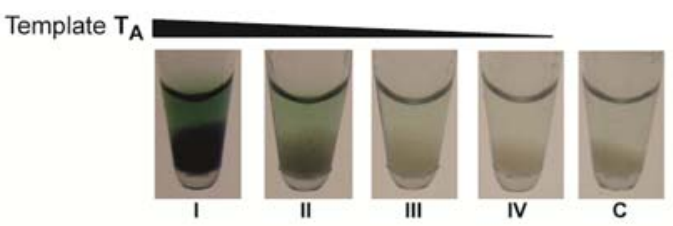

(B)

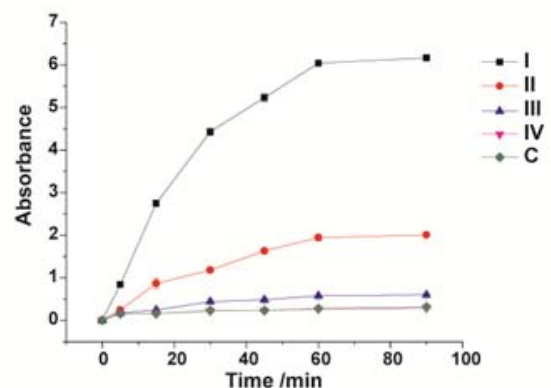

(C) $5^{*}$-biotin-...TC $3^{\prime}$-...AG

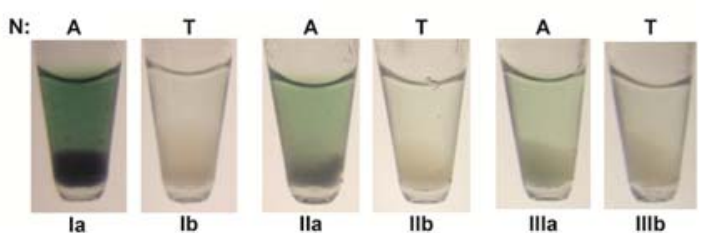

Figure 3. (A) Detection limit identification by processing of $\mathbf{d T}^{*} \mathbf{T P}$ with KlenTaq DNA polymerase at $37{ }^{\circ} \mathrm{C}$ in the presence of different concentrations of template $\left(\mathbf{T}_{\mathrm{A}}\right)$, followed by RCA and hybridisation with G-quadruplex DNAzymes. Signal identification via peroxidase-like activity of the complex hemin/hybridised Gquadruplex DNA strand. Concentration template $\mathbf{T}_{\mathbf{A}}$ : test tube I: $100 \mathrm{nM}$; test tube II: $10 \mathrm{nM}$; test tube III: $1 \mathrm{nM}$; test tube IV: $0.1 \mathrm{nM}$. Control experiment: test tube C: $100 \mathrm{nM}$ template $\mathbf{T}_{\mathbf{A}}$, experiment performed without $\mathbf{d T} * \mathbf{T P}$. The pictures were taken after $1 \mathrm{~h}$. (B) ABTS absorption at $420 \mathrm{~nm}$ recorded in function of the time after addition of hemin, $\mathrm{ABTS}^{2}$, and $\mathrm{H}_{2} \mathrm{O}_{2}$ in caco. KTD buffer $10 \mathrm{mM}$ to the beads. The time points were taken after: $5,15,30,45,60$, and 90 min. Concentration canonical template $\left(\mathbf{T}_{\mathbf{A}}\right): 100 \mathrm{nM}$ (I, 3 pmol, black line), $10 \mathrm{nM}$ (II, $0.3 \mathrm{pmol}$, red line), $1 \mathrm{nM}$ (III, $30 \mathrm{fmol}$, blue line), $0.1 \mathrm{nM}$ (IV, $3 \mathrm{fmol}$, magenta line), and control (C, green line). (C) Partial DNA sequence of primer and template. Discrimination experiments: template $\mathbf{T}_{\mathbf{A}}$ /template $\mathbf{T}_{\mathbf{T}}$ (sequences details Supplementary information). Template $\mathbf{T}_{\mathbf{A}}$ concentrations: test tubes Ia $(100 \mathrm{nM})$, IIa $(10 \mathrm{nM})$, and IIIa (1 nM); template $\mathbf{T}_{\mathbf{T}}$ : test tubes Ib $(100 \mathrm{nM})$, IIb $(10 \mathrm{nM})$, and IIIb $(1 \mathrm{nM})$. The pictures were taken after $1 \mathrm{~h}$. due to processing of $\mathbf{d T}^{*} \mathbf{T P}$ (Fig. 1). Subsequently, the beads were washed and incubated with the G quadruplex containing DNA strand (G4). After washing, hemin, ABTS ${ }^{2}$, and $\mathrm{H}_{2} \mathrm{O}_{2}$ were added to the reaction mixture. The results are depicted in Figure $3 \mathrm{~A}$. As underlined before, a most reliable colour read out was achieved $1 \mathrm{~h}$ after the addition of $\mathrm{H}_{2} \mathrm{O}_{2}$ (Fig. 3B). As negative control a reac tion in the absence of $\mathbf{d T}^{*} \mathbf{T P}$ was performed, and no significant col our change was detected. We observed a detection limit of $1 \mathrm{nM}$ (30 fmol) concentration of template $\mathbf{T}_{\mathbf{A}}$ (Fig. 3A). Thus, the isother mal amplification resulted in a 50 fold increase of sensitivity com pared to the control reaction without RCA or the previously published approach. ${ }^{17}$ Next we evaluated the ability of the method to discriminate between the two DNA targets differing only in one nucleotide position. The experiment was carried out as mentioned before either in the presence of the canonical template $\left(\mathbf{T}_{\mathbf{A}}\right)$ or the non canonical template ( $\mathbf{T}_{\mathbf{T}}$ ) (Fig. $3 \mathrm{C}$ ). Only in the presence of the canonical target $\mathbf{T}_{\mathbf{A}}$ a significant colour change was detected at the lower concentration of $1 \mathrm{nM}$.

Taken together, we developed a system that can be applied for identification of DNA at single base resolution and allows detec tion by the naked eye. The method is based on the sequence selec tive incorporation of an ODN modified nucleotide by a DNA polymerase extending an immobilized primer. Due to the ability of DNA polymerases to use the oligonucleotide strand tethered to the modified nucleotide as a second primer, we were able to per form rolling circle amplification. The sequence selective extension of the immobilized primer by processing of $\mathbf{d T}^{*} \mathbf{T P}$, combined with RCA experiments and hybridisation of the isothermally extended DNA strand with G quadruplex DNAzymes, allowed us to generate an amplified signal that can be exploited for DNA detection by naked eye with significantly increased sensitivity compared to an earlier system. ${ }^{17}$

\section{Acknowledgements}

We gratefully acknowledge the DFG, Alexander von Humboldt Foundation and the Konstanz Research School Chemical Biology for their support.

\section{Supplementary data}

Supplementary data (synthetic details for modified dTTP, exper imental details for PEX, absorption spectra, solid support reaction, and buffer solution used) associated with this article can be found, in the online version, at http://dx.doi.org/10.1016/j.bmcl.2015.12. 082 .

\section{References and notes}

1. (a) Turner, A. P. F. Chem. Soc. Rev. 2013, 42, 3184; (b) Wang, F.; Freage, L.; Orbach, R.; Wilner, I. Anal. Chem. 2013, 85, 8196; (c) Sassola, A.; Leca-Bouvier, B. D.; Blum, L. J. Chem. Rev. 2008, 108, 109; (d) Sawyers, C. L. Nature 2008, 452, 548.

2. Debouck, C.; Goodfellow, P. N. Nat. Genet. 1999, 21, 48.

3. Palchetti, I.; Mascini, M. Analyst 2008, 133, 846.

4. Divne, A. M.; Allen, M. Forensic Sci. Int. 2005, 154, 111.

5. Niemz, A. T.; Ferguson, M.; Boyle, D. S. Trends Biotechnol. 2011, 29, 240.

6. (a) de-Paz, H. D.; Brotons, P.; Munoz-Almagro, C. Expert Rev. Mol. Diagn. 2014, 14, 827; (b) Park, J. S.; Cho, D. H.; Yang, J. H.; Kim, M. Y.; Shin, S. M.; Kim, E. C.; Park, S. S.; Seong, M. W. Ann. Lab. Med. 2013, 33, 39.

7. (a) Tanaka, K.; Iwashita, M.; Matsushima, M.; Wachi, Y. Izawa, T.; Sakai, K.; Kobayashi, Y. J. Matern-Fetal Neonat. Med. 2015, 1; (b) Jeong, Y.-J.; Park, K.; Kim, D.-E. Cell. Mol. Life Sci. 2009, 66, 3325; (c) Andras, S. C.; Power, J. B.; Cocking, E. C.; Davey, M. R. Mol. Biotechnol. 2001, 19, 29.

8. (a) Notomi, T: Mori, Y: Tomita, N. Kanda, H. J Microbiol 2015, 53, 1; (b) Notomi, T.; Okayama, H.; Masubuchi, H.; Yonekawa, T.; Watanabe, K.; Amino, N.; Hase, T. Nucleic Acids Res. 2000, 28, e63.

9. (a) Walker, G. T.; Fraiser, M. S.; Schram, J. L.; Little, M. C.; Nadeau, J. G.; Malinowski, D. P. Nucleic Acids Res. 1992, 20, 1691; (b) Cheng, W.; Zhang, W.; Yang, Y. R.; Shen, B.; Zhu, D.; Lei, P. H.; Ding, S. J. Biosens. Bioelectron. 2014, 62, 274. 
10. (a) Deng, R.; Tang, I.; Tian, Q.; Wang, Y.; Lin, L.; Li, J. Angew. Chem., Int. Ed. 2014 53, 2389; (b) Jiang, D. N.; Liu, F.; Liu, C.; Liu, L. L.; Li, Y.; Pu, X. Y. Anal. Methods 2014, 6, 1558; (c) Cheglakov, Z.; Weizmann, Y.; Braunschweig, A. B.; Wilner, O. I.; Willner, I. Angew. Chem., Int. Ed. 2008, 47, 126; (d) Lin, C.; Wang, X.; Liu, Y. Seeman, N. C.; Yan, H. J. Am. Chem. Soc. 2007, 129, 14475.

11. (a) Li, X.; Wang, Y.; Wang, L.; Wei, Q. Chem. Commun. 2014, 5049; (b) Vincent, M.; Xu, Y.; Kong, H. EMBO Rep. 2004, 5, 795.

12. Oh, S. J.; Park, B. H.; Jung, J. H.; Choi, G.; Lee, D. C.; Kim, D. H.; Seo, T. S. Biosens. Bioelectron. 2016, 75, 293.

13. Sun, X.-C.; Wang, Y. L.; Yang, L.; Zhang, H. J. Virol. Methods 2015, 211, 12.

14. Tram, K.; Kanda, P.; Salena, B. J.; Huan, S.; Li, Y. Angew. Chem., Int. Ed. 2014, 53, 12799.
15. Tian, Y.; He, Y.; Mao, C. ChemBioChem 1862, 2006, 7.

16. Liu, Y. L.; Fu, W. L.; Li, C. M.; Huang, C. Z.; Li, Y. F. Anal. Chim. Acta 2015, 861, 55

17. Verga, D.; Welter, M.; Marx, A. Chem. Commun. 2015, 7379.

18. Baccaro, A.; Steck, A.-L.; Marx, A. Angew. Chem., Int. Ed. 2012, 51, 254

19. (a) Du, F.; Tang, Z. ChemBioChem 2011, 12, 43; (b) Li, D.; Shlyahovsky, B.; Elbaz, J.; Willner, I. J. Am. Chem. Soc. 2007, 129, 5804; (c) Xiao, Y.; Pavlov, V.; Niazov, T.; Dishon, A.; Kotler, M.; Willner, I. J. Am. Chem. Soc. 2004, 126, 7430; (d) Travascio, P.; Li, Y.; Sen, D. Chem. Biol. 1998, 5, 505; (e) Li, Y.; Sen, D. Biochemistry 1997, 36, 5589.

20. Davies, H. et al Nature 2002, 417, 949.

21. Blanco, L.; Bernard, A.; Lazaro, J. M.; Martin, G.; Garmendia, C.; Salas, M. J. Biol. Chem. 1989, 8935. 